\title{
NON INVASIVE DISTRESS MONITORING IN CHILDREN HOSPITAL INTENSIVE CARE UNIT
}

\author{
L.Bocchi, L.Spaccaterra ${ }^{1}$, F.Acciai, S.Orlandi, F.Favilli, E.Atrei ${ }^{1}$, C.Manfredi, G.P.Donzelli ${ }^{1}$ \\ Department of Electronics and Telecommunications, Università degli Studi di Firenze, Via S. Marta 3, 50139 Firenze, Italy \\ manfredi@ det.unifi.it \\ ${ }^{1}$ Department of Pediatrics, AOU A. Meyer-Università degli Studi di Firenze, Via L. Giordano, Firenze, Italy \\ donzelli@unifi.it
}

Keywords: Intensive care, non-invasive monitoring, blood oxygenation, newborn cry analysis.

\begin{abstract}
First results are presented concerning the evaluation of the distress occurring during cry, as related to possible decrease of central and peripheral blood oxygenation. A recording system has been developed, that allows synchronised, non invasive, monitoring of both central and peripheral blood oxygenation along with audio recordings of newborn infant's cry. Ad hoc markers allow for localisation of cry episodes in blood oxygenation recordings. A multi-purpose voice analysis tool (BioVoice), characterised by high resolution and tracking capabilities, is used to extract main cry features. The method has been applied to a set of 18 preterm and 2 full-term newborns at the intensive care unit, A.Meyer Children Hospital, Firenze, Italy.
\end{abstract}

\section{Introduction}

Preterm and low-birth-weight infants often present respiratory problems, ranging to insufficient ventilation to apnoea. Also, new born infants have an impaired auto regulation of the cerebral blood flow [1, 2, 3, 4]. Irregularities in the blood flow and pressure may adversely influence the development of the child $[5,6,7,8]$. Some studies have been performed to evaluate both cerebral and peripheral blood oxygenation in the newborn by Near Infrared Spectroscopy (NIRS) and pulsioxymetry, also as linked to other techniques [1]-[6], [14]. Though crying is a physiological action made by the infant to communicate and draw attention, in preterm and/or low-birthweight infants it could imply an effort which may have an adverse impact on blood oxygenation. From our previous studies [ ], the distress effect of crying seems much larger on central blood saturation than on peripheral saturation.

To this aim, a new recording system has been developed, that allows non invasive synchronised monitoring of blood oxygenation (NIRS spectrometer and pulsioxymeter) and the audio recording of infant's cry emissions. Preliminary results on a data set of 20 preterm infants indicate that often the effort in crying is linked to a noticeable decrease in the central oxygenation level during a cry episode. Objective analysis of cry signals gives helpful parameters for comparison.

\section{Materials and methods}

Monitoring has been performed by collecting data from three different sources: heart rate and peripheral blood saturation of oxygen were recorded using a pulsioxymeter, central blood saturation was measured with a NIRS device, and a microphone connected to a laptop has been used to record cry emissions. Specific software was developed to synchronise data during recordings. Figures 1-2 respectively depict the experimental setup and the user interface for patient's data collection, device selection and synchronized data acquisition.

\subsection{Devices}

Central blood saturation has been measured by means of a NIRS device (somasensors by INVOS 5100C Somanetics Corp.), with sampling rate of 0.2 samples/sec. The NIRS signal is composed of up to four independent channels, each made up of two data, one containing the relative saturation of oxygen, and the other representing the quality of the signal, useful to detect possible artifacts related to patient movement or poor contact of the sensor with the patient.

Peripheral blood oxygenation and heart rate were recorded with a pulsioxymeter (Radical Masimo Set) that employs powerful adaptive digital filters for denoising. It allows for both venous and arterials blood oxygenation, with a sampling rate of 1 sample/sec.

A unidirectional microphone (Shure SM58), equipped with Tascam US-144 portable audio/MIDI interface $(96 \mathrm{kHz} / 24-$-bit recording) has been used to record cry emissions. Audio recordings were stored on a multimedia laptop on a single channel audio track, with sampling rate $F s=44 \mathrm{kHz}$ and 16 bit resolution.

Specific software has been designed and implemented to allow synchronization of the output of the three devices by means of a digital output linking the laptop with the input of both the NIRS and pulsioxymeter devices. The software implements simultaneous recording of the audio channel trough the US-144 board and of the NIRS and pulsioxymeter signal using a RS-232 connection.

Due to different sampling rates used for NIRS, pulsioxymeter and audio signals, in order to synchronise data the range for 
audio analysis is adjusted to the nearest second in the corresponding NIRS recording. Markers are provided on the oxygenation recordings, corresponding to cry episodes.

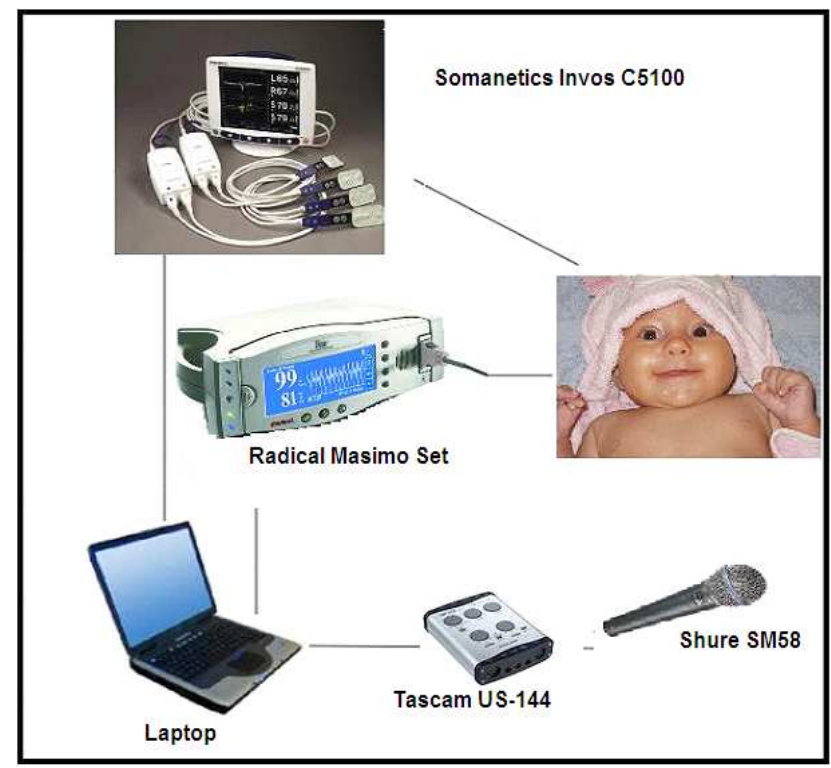

Figure 1: Devices for data acquisition and elaboration.

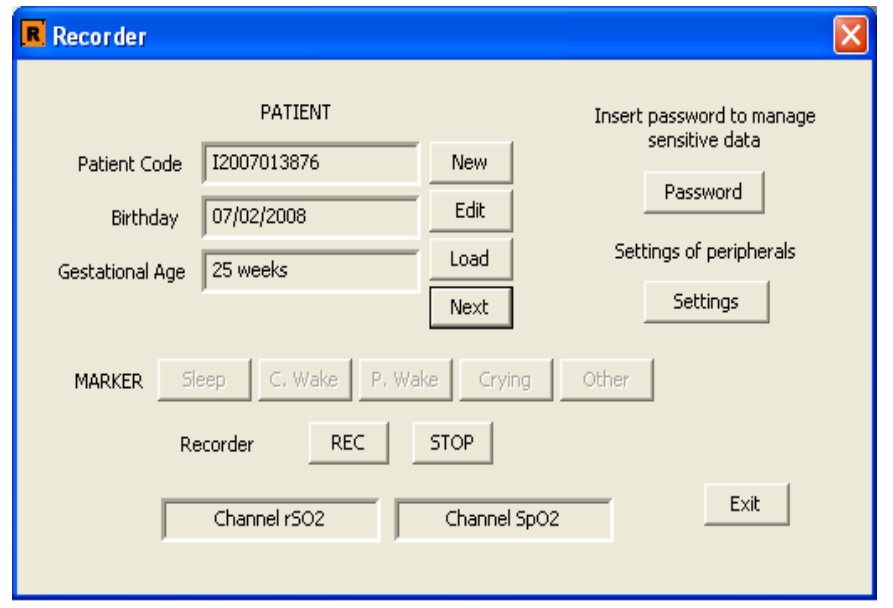

Figure 2: User interface for storage and retrieval of patient's data, selection of recording devices, and recording options.

Signals were recorded in a quiet room at the Intensive Care Unit, satisfying the basic environmental requirements:

- Low background noise, as the room can be successfully insulated from the outside.

- Levels of illumination can be selected and kept stable according to the NIRS device requirements

Moreover, both oxymetry instruments are sensitive to sudden movements possibly made by the patient. Hence, special care has been used to assure a good contact between sensors and the patient skin.

\subsection{Cry signal analysis}

Cry episodes ( $2 \mathrm{sec}-5 \mathrm{sec}$ length) are automatically extracted from audio recordings by means of an off-line devoted software tool, and then submitted to a multi-purpose voice analysis tool (BioVoice). Fig.3 shows the user-friendly interface. The tool has been developed to overcome some weakness commonly found in most commercial software. Specifically, non manual setting is required to the user; on each cry episode a voiced/unvoiced (V/UV) separation algorithm is applied, specifically optimised to avoid parameter estimation on signal frames that have no harmonic content, where misleading results could be obtained [7].

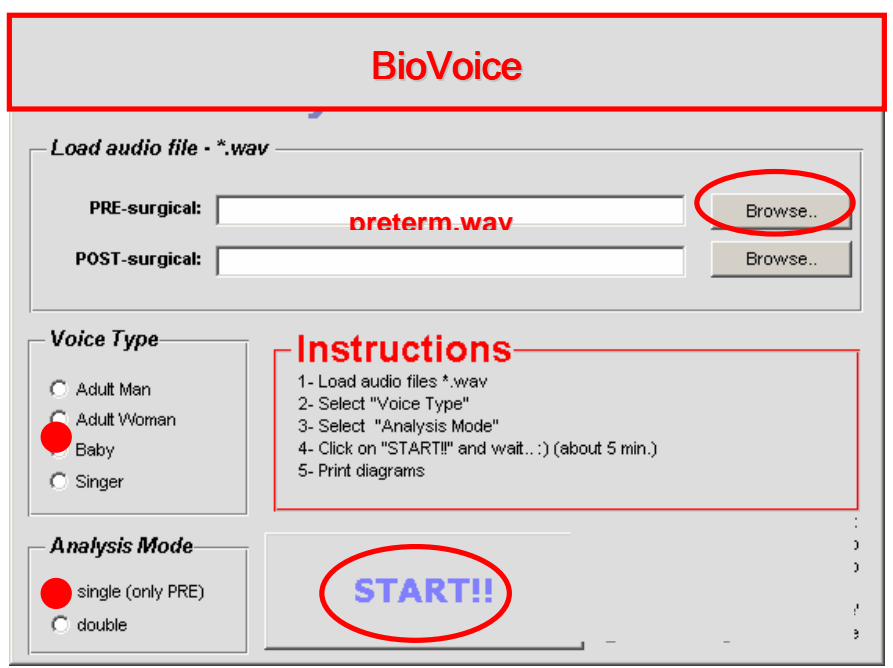

Figure3: The user-friendly interface of the voice analysis tool

Moreover, BioVoice performs $\mathrm{F}_{0}$ and resonance frequencies (RFs) tracking on signal frames of varying length (even few $\mathrm{ms}$ ), adaptively tailored to varying signal characteristics.

$\mathrm{F}_{0}$ tracking is achieved by means of a two-step procedure, based on well-established results: the AMDF approach is applied to a wavelet-smoothed SIFT estimation of $\mathrm{F}_{0}$, with optimised and varying adaptive filter order [8]-[10].

Even if vowel frequencies cannot be found in newborn cry, RFs $\left(F_{i}, i=1, ..\right)$ reflect important acoustical characteristics of the vocal tract of the infant. Robust and high-resolution RFs estimation is implemented, based on parametric AutoRegressive (AR) PSD evaluation.

Finally, a number of plots and tables is displayed and saved in printable format, for a visual comparison of results. Specifically, $F_{0}$, V/UV frames, spectrogram and the first three RFs, $F_{1}-F_{3}$, are plotted, all in coloured map. Tables summarise mean, std, max, min values for $F_{0}$ and $F_{1}-F_{3}$, as well as cry length and the corresponding maximum energy. These parameters are in fact considered among the most meaningful for newborn cry analysis [8]-[12].

\section{Experimental results}

The analysis has been carried out on a group of 18 preterm (23weeks $<$ g.a. $<37$ weeks) and/or low weight $(590 \mathrm{~g}<$ w.a.b. $<2500 \mathrm{~g})$ infants and 2 full term infants (38 weeks $<$ g. $<<40$ weeks, $2600 \mathrm{~g}<$ w.a. $b<3460 \mathrm{~g}$ ), selected by physicians among patients at the Critical Care Unit of the Children Hospital A.Meyer, in Firenze, Italy. No relevant pathology was found among the analysed infants. Fig.3 and Table 1 show results from BioVoice, concerning a cry 
episode of a newborn infant with gestational age of 27 weeks and a birth weight of $800 \mathrm{~g}$.
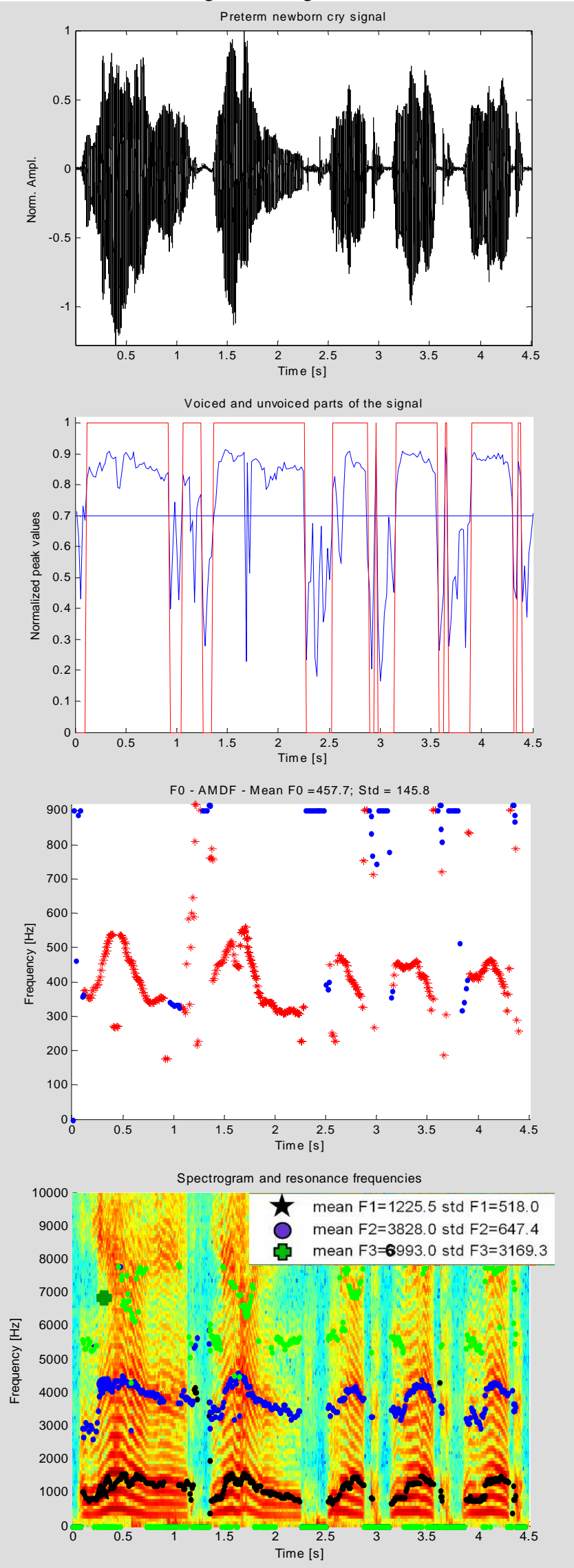

Figure 3: From top to bottom: cry episode, V/UV separation, $\mathrm{F}_{0}$ tracking, $\mathrm{F}_{1}-\mathrm{F}_{3}$ superimposed on the spectrogram.

Notice that, as for most cases, due to staying for a due period in the incubator, recordings were made later (age $>35$ weeks). Results show that cry episodes are quite short $(<1 \mathrm{~s})$. F0 shows typical rising-falling melody, but with decreasing intensity with time, possibly due to reduced breathing energy of the patient. The same seems true for F1-F3. Fig. 4 shows 20 min NIRS tracking, where the most right frame includes the cry episode cited above. A decrease in blood oxygenation corresponding to cry is clearly visible, as well as in the other two frames, in the same figure, pointing out distress episodes related to crying. This happens in all cases.

Moreover, tracking the saturation level often pointed out an increase of saturation after the episode, possibly due to an effort made by the nervous system to compensate the loss of oxygen due to crying [14].

To test the results, the mean of 5-10-15 NIRS values respectively (corresponding to about $25-50-75 \mathrm{sec}$ ) before and after each cry episode were considered, and compared for all cases. A t-test applied on such data shows in most cases a highly statistical difference $(<0.01)$ between pre- and post crying NIRS values. However, we point out that data are in general not homogeneous, due to different situations: cry episodes can be close to each other or not, and possibly preceeded by sleep or awakness or other conditions. This could distort results.

First results from the whole group of preterm newborns show that in most cases drop in blood oxygenation seems directly related to the distress due to crying, pointing out the need for specific care in preterm infants devoted to stress reduction.

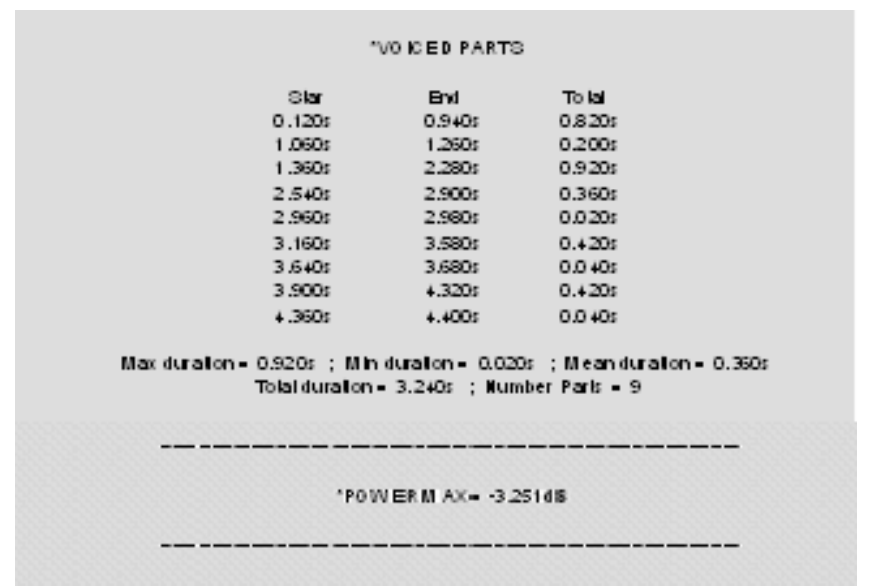

Table 1: Statistics of the cry episode in Fig.3.

\section{Final remarks}

First results have been presented, concerning the evaluation of the distress occurring during cry, as related to possible decrease of cerebral oxygenation. A synchronisation system has been developed, that allows simultaneously recording blood oxygenation and infant's cry emissions. Cry episodes are A new robust tool for new-born infant cry analysis is presented. Specifically, possible relationships among some cry parameters and distress are investigated here, as related to the decrease of cerebral oxygenation. 


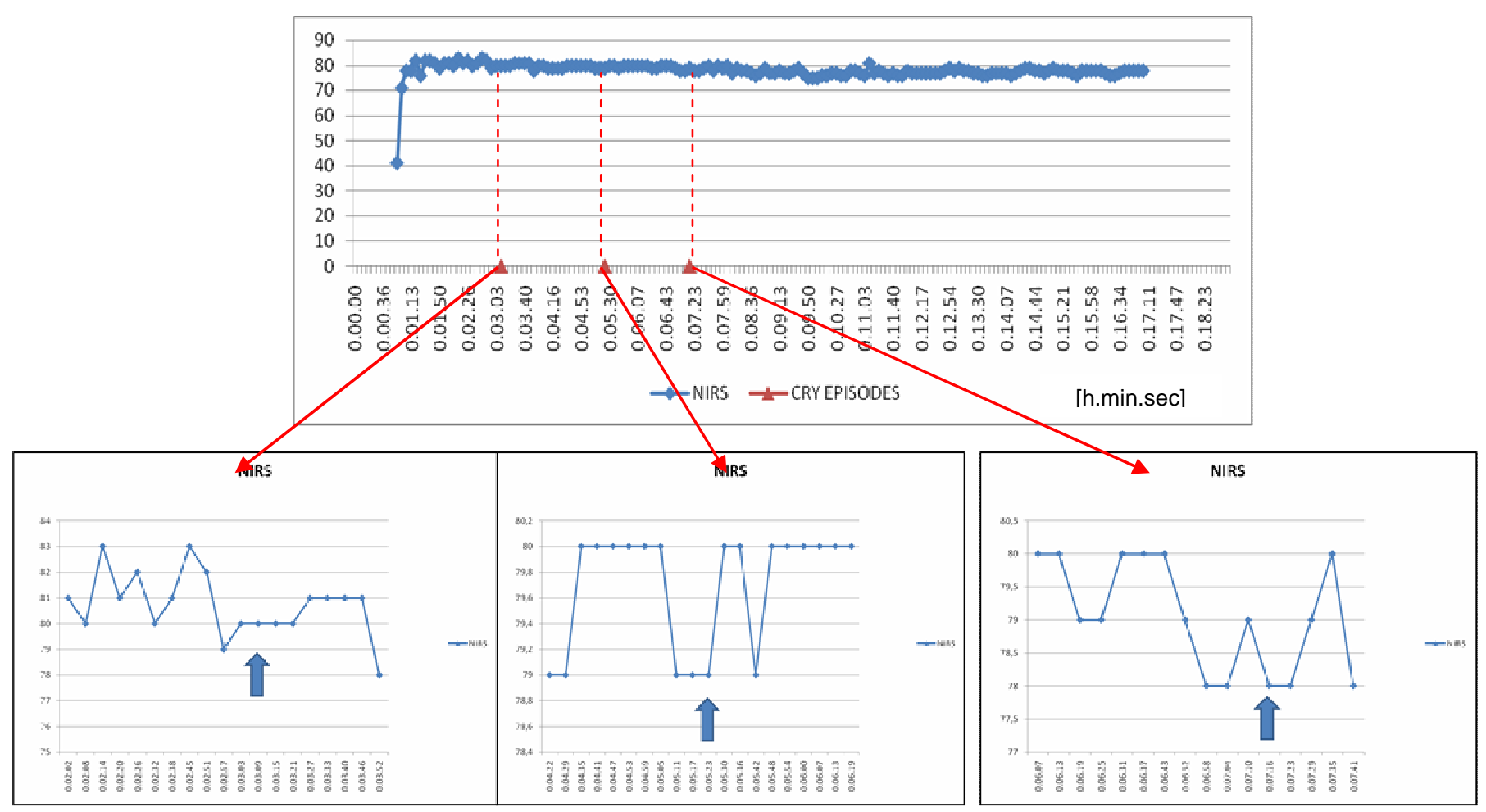

Figure 4: Upper: Plot of 18.23 min recording of central blood oxygenation (NIRS). Lower: three frames from the upper figure ( $\mathbf{\Delta})$ of about $2 \mathrm{~min}$. length each, including a cry episode ( $)$, always corresponding to a decrease in blood oxygenation level.

\section{Acknowledgements}

This work has been partially supported by "Ente Cassa di Risparmio di Firenze", under the project: n. 2006.1517 "Analisi di segnali ed immagini vocali per applicazioni biomediche", 2007.

\section{References}

[1] Pryds O. \& Edwards, A.D., "Cerebral blood flow in the newborn infant", Archives of Disease in Childhood: fetal and neonatal edition,74 (1), pp. 63-69, (1996).

[2] Greisen G. "Cerebral blood flow preterm infant during the first week of life", Acta Paediatrica Scandinavica, 75, pp.43-51 (1986).

[3] Lou H.C., Lassen N.A. \& Frii-Hansen B. (1979). Impaired autoregulation of cerebral blood flow in the distressed new born infant. Journal of Pediatrics, 94, 118-121.

[4] Lou, H.C. (1994). Hypoxyc-hemodinamic pathogenesis of brain lesion in the newborn. Brain \& Development, 16, 423-431.

[5] Miall-Allen V.M., de Vries L.S., Whitelaw A.G. (1987). Mean arterial blood pressure and neonatal cerebral lesion. Archives of Disease Childhood, 62, 1068-1069.

[6] Van De Bor M. \& Walther F.J., "Cerebral blood flow velocity regulation in preterm infant", Biology of the Neonate, 59, pp. 329-335, (1991).

[7] Perry, E.H., Bada H.S., Ray J.D., Korones S.B., Arheart K. \& Magill H.L., "Blood pressure increases, birth weigh-dependent stability boundary, and intraventricular haemorrhage", Pediatrics, 85, pp. 727-732, (1990).

[8] Friis - Hansen B., "Perinatal brain injury and cerebral blood flow in newborn infant", Acta Paediatrica Scandinavica, 74, pp. 323-331, (1985).
[9] Delpy DT., Cope MC., Cady EB, Wyatt JS.,Hamilton PA., Hope PL, Wray S. \& Reynolds EO., "Cerebral monitoring in newborn infants by magnetic resonance and near infrared spectroscopy", Scandinavian Journal of Clinical Laboratory Investigation, 188, pp. 9-17, (1987).

[10]Fort, A. Ismaelli, C. Manfredi, P. Bruscaglioni, "Parametric and non parametric estimation of speech formants: application to infant cry", Med. Eng. Phys., 18 (8), pp. 677-691(1996).

[11]Fort, C. Manfredi, "Acoustic analysis of new-born infant cry signals", Med. Eng. Phys., 20 (6), pp.432-442 (1998).

[12]Wermke K., Mende W., Manfredi C., Bruscaglioni P., "Developmental Aspects of infant's Cry melody and Formants", Med. Eng. Phys, 24 (7-8), pp. 501-514 (2002).

[13]Manfredi C., Tocchioni V., Bocchi L., "A robust tool for newborn infant cry analysis", $28^{\text {th }}$ Annual Int. Conf. IEEE EMBS, Aug.30- Sept. 3, 2006, New York City, U.S.A.

[14]Nicollas R., Ouaknine M., Giovanni A., Berger J., To J.P., Dumoulin D., Triglia J.M., " Physiology of vocal production in the newborn", Proc. $3^{\text {rd }}$ Int. Workshop MAVEBA, Firenze, Italy, December 2003, pp. 51-54.

[15]Escobedo D., Cano S., Collo E., Regueiferos L., Capdevila L., "Rising shift of pitch frequency in the infant cry of some pathologic case", Proc. $2^{\text {nd }}$ Int. Workshop MAVEBA, Firenze, Italy, September 2001.

[16] http://www.disat.unimib.it/bioacoustics/it

[17]Bocchi L., Spaccaterra L., Acciai F., Orlandi S., Favilli F., Atrei E., Manfredi C., Donzelli G.P., "Monitoring of preterm infants during crying episodes", $11^{\text {th }}$ Conference MEDICON 2007, Ljubljana, Slovenia, June 26-30, 2007.

[18]Bocchi L., Spaccaterra L., Acciai F., Orlandi S., Favilli F., Atrei E., Manfredi C., Donzelli G.P., "Blood oxygenation vs cry in preterm newborn infants", Proc. $5^{\text {th }}$ Int. Workshop MAVEBA, Firenze, Italy, Dec. 2007, pp. 215-218 (2007). 